\title{
Distribution of GABA-like immunorreactivity in guinea pig vestibular cristae ampullaris
}

\author{
Iván López, José M. Juiz ${ }^{2}$, Richard A. Altschuler ${ }^{2}$ and Graciela Meza ${ }^{1}$ \\ 'Departamento de Neurociencias, Instituto de Fisiología Celular, UNAM, México D.F. (México) and ${ }^{2}$ Kresge Hearing Research Institute, \\ The University of Michigan, Ann Arbor, Michigan (U.S.A.)
}

(Accepted 10 July 1990)

Key words: $\gamma$-Aminobutyric acid; Vestibular cristae ampullaris; Guinea pig; Post-embedding immunocytochemistry

\begin{abstract}
Post-embedding immunocytochemical techniques were used to assess distribution of $\gamma$-aminobutyric acid (GABA) in the guinea pig cristae ampullaris. GABA-like immunoreactivity (GABA-LIR) was found in the cytoplasm of both type I (HCI) and type II hair cells (HCII), in the afferent calyx $(\mathrm{AC})$ contacting $\mathrm{HCI}$ and some myelinated fibers in the subjacent stroma. $\mathrm{HCI}$ and its calyceal contacts showed variation in GABA-LIR, suggesting different populations in $\mathrm{HCI}$ and AC. These results support a putative afferent neurotransmitter role of GABA in $\mathrm{HC}$ and a possible degradation site of GABA in AC.
\end{abstract}

Several lines of evidence suggest a putative afferent neurotransmitter role for $\gamma$-aminobutyric acid (GABA) in the vestibular sensory periphery, since GABA synthesis has been shown in most vertebrate groups' vestibular homogenates (i.e. skate and bullfrog ${ }^{4}$, green frog ${ }^{9}$, chick $^{9,12}$, rat $^{9}$ and guinea pig $^{9}$ ). Some experimental manipulations suggest that GABA synthesis takes place in vestibular hair cells. Glutamic acid decarboxylase (GAD), the key enzyme of synthesis of GABA, is present in the vestibular periphery but does not decrease after frog eighth nerve ablation ${ }^{10}$. During development of chicks $^{14}$, rats $^{11}$ and guinea pigs ${ }^{7}$, vestibular GAD parallels the maturation of hair cells and is not modified by the arrival of the efferent innervation. Furthermore, streptomycin treatment in the guinea pig which causes degeneration of vestibular hair cells and has no action on nerve terminals results in GAD vestibular depletion ${ }^{15}$.

Electrophysiological experiments have shown that iontophoretically applied GABA increases spontaneous responses in the isolated cat labyrinth and that picrotoxin and bicuculline inhibit this action ${ }^{3}$. This suggests the presence of $\mathrm{GABA}_{\mathrm{A}}$ receptors in vertebrate statoacoustic organs, a notion supported by the biochemical and pharmacological characterization of GABA receptors in chick vestibular membranes ${ }^{13}$. On the contrary, GABA perfusion of amphibian isolated semicircular canals had no effect on the firing rate of afferent fibers ${ }^{1,5}$. Some pre-embedding immunocytochemical experiments also show controversial findings; in the chick, $\mathrm{GABA}^{18}$ and GAD-like immunoreactivity was shown to be confined to vestibular hair cell cytoplasm, while GABA-T (the GABA degrading enzyme) was found around hair cells and along nerve fibers running through the vestibular stroma ${ }^{17}$. In other experiments, GABA-like immunostaining was found in fibers and bouton-type terminals ${ }^{19}$ or calyceal nerve endings surrounding type I hair cells ${ }^{2}$.

In order to contribute to the correct localization of the GABA system in vestibular sensory periphery, in the present report we will describe our post-embedding GABA-like immunoreactivity (GABA-LIR) findings in guinea pig vestibular ampullary cristae at the light microscopic level by using a GABA antiserum whose properties have been described extensively ${ }^{20}$. Parts of the present work have been presented in abstract form ${ }^{8}$.

Five healthy (both sexes) young pigmented guinea pigs (Cavia cobaya) (200-300 g weight) were used in this study. They were overanesthetized with chloral hydrate $(1.2 \mathrm{~g} / \mathrm{kg}$ weight $)$, exsanguinated transcardially with $50 \mathrm{ml}$ of physiological saline solution, and perfused with $750 \mathrm{ml}$ of a fixative containing $4.0 \%$ paraformaldehyde (Polysciences) and $0.2 \%$ glutaraldehyde (Electron Microscopy Sciences, EMS) in $0.1 \mathrm{M}$ sodium cacodylate buffer (EMS) (300 mOsm) $\mathrm{pH} 7.4$ delivered over a 15 -min time period. At the end of the perfusion, the auditory bullae were opened, and the vestibular organs were removed and immersed in the same fixative for $3 \mathrm{~h}$. The tissue was post-fixed in osmium tetroxide (EMS) $(0.1 \%$, in sodium cacodylate buffer, pH 7.4, $1 \mathrm{~h}$ ), dehydrated through a graded ethanol series and propylene oxide, and embedded in 812-based resin (EMS). One- $\mu \mathrm{m}$ thick sections of

Correspondence: G. Meza, Departamento de Neurociencias, IFIC, UNAM, Apartado Postal 70-600, 04510 México D.F., México. 
the embedded tissue were then made with an ultramicrotome (Reichter Ultracut or LKB Ultratome) and mounted onto glass microscope slides. Resin was removed by incubating them with saturated sodium ethoxide solution diluted 1:1 with absolute ethanol. The sections were sequentially washed in ethanol $(1 \times 1 \mathrm{~min})$, and distilled water $(3 \times 5 \mathrm{~min})$. Then, they were submerged into $1 \%$ aqueous sodium meta-periodate for 5 min alternated by a brief distilled water wash. Following additional distilled water rinses $(3 \times 5 \mathrm{~min})$, the slides were incubated sequentially in (1) $3 \%$ normal goat serum (Vector Labs) in phosphate-buffered saline (PBS) $0.1 \mathrm{M}$,

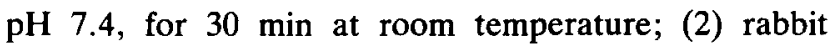
anti-GABA serum ${ }^{20}$ dilutions 1:100, 1:250, 1:500 or $1: 1000$ in PBS for $48 \mathrm{~h}$ at $4^{\circ} \mathrm{C}$; (3) the avidin-biotinylated peroxidase bridge method was used to visualize the immunohistochemical reaction: biotinylated goat antirabbit IgG (Vector Labs) for $1 \mathrm{~h}$; avidin-biotinylatedhorseradish peroxidase complex (Vectastain Reagent, Vector Labs) for $1 \mathrm{~h}$; and 3,3'-diaminobenzidine (DAB$\mathrm{H}_{2} \mathrm{O}_{2}$ ) for 3-5 min, according to previously described methods 6 .

The specificity of the immunostaining was tested following the above protocol but (a) using the primary antiserum preabsorbed with an excess of GABA conjugated with glutaraldehyde to bovine serum albumin, (b) replacing the GABA-antiserum by $\mathrm{PBS}$ or (c) adding 10 mM GABA (final concentration) in the GABA antiserum suspension. Different dilutions of this latter (from 1:100 to $1: 1000$ ) decreased background accordingly. Therefore, the results obtained using 1:1000 are described below.

GABA-LIR was confined to the cytoplasm of both type I and type II hair cells and to some myelinated fibers in the subjacent stroma (Fig. 1A). No immunoreactivity was encountered either when (a) the technique was followed using preincubated GABA antiserum with GABA conjugated to BSA (Fig. 1B) or (b) by replacing the GABA antiserum with PBS (not shown). Furthermore, preincubation with free GABA did not decrease specific immunostaining (results not shown). Type I and II hair cells, however, stained differently. While type II cells were intensely immunoreactive and their staining did not vary with the location of the cells within the cristae ampullaris (CA), type I cells showed graded GABA-LIR intensity: some were intensely stained, others moderately stained and some others were definitely unstained (Fig. 2). This distribution was mainly observed at the upper portion of the CA. The lower part showed a uniform, intense GABA-LIR pattern in both type I and II hair cells. Some nerve fibers arriving in the sensory epithelium were also immunoreactive (Fig. 3A). These fibers correspond to the calyceal afferent endings making contact with type I hair cells (Fig. 3B). In the upper part of the CA, GABA-LIR in the afferent calyx showed, as in type I hair cells, graded immunoreactivity, ranging from intense to absent (Fig. 2). In the basolateral region, the staining of both nerve fibers in the stroma and the calyces was constant and intense. Finally, no immunoreactivity was found in supporting cells.

The present study is the first in the literature to study GABA-LIR in the vestibule with post-embedding immunocytochemical techniques. It provides evidence that GABA-LIR is found both in hair cells and in afferent fibers of the guinea pig CA; however, the immunostaining showed various patterns: we observed that staining intensities of type II hair cell were homogeneous, while type I hair cell showed variations in intensity of the GABA-immunoreactive material, permitting us to classify them tentatively into 3 groups: (a) strongly immunoreactive, (b) moderately immunoreactive and (c) nonimmunoreactive (Fig. 2). As to the nerve fibers, although at low magnification they were homogeneous, when observed at higher power, the same classification applies: (a) strongly immunoreactive, (b) moderate or (c) absence of GABA-LIR. Accordingly, 3 types of situations can occur: GABA-LIR in both type I and type II hair cells, but not in the calyx; GABA-LIR in type I cell and its afferent calyx and GABA-LIR in the calyx but not in the cell.

The presence of GABA-LIR in type I and II hair cells, except for some type $I$ in the upper part of the CA and some fibers of the stroma conforms well with recent immunocytochemical findings of both GABA and GADlike immunoreactivity in both cell and I and II in CA and in some fibers of the stroma of the chick $^{18}$.

GABA-LIR in some calyceal terminals either alone or contacting a GABA-LIR positive hair cell I resembles a recent study in the guinea pig vestibular organs, in which GABA-LIR was found in all calyces of $\mathrm{CA}^{2}$.

Although taken altogether our results suggest an important role of GABA in the vestibule, they provide no direct evidence for their functional significance; therefore only speculations can be made. GABA-LIR moderately to intensely positive in type I and II hair cells as it was shown in the chick, is in complete accordance with earlier indirect interpretations of a GABA afferent neurotransmitter role in the vertebrate vestibule ${ }^{10,14,15}$. In this respect, differences in the pattern of GABA-LIR have been reported in the amacrine layer of the cat retina in which staining intensities of these cells ranged from moderate to heavy, suggesting variations in the amount of GABA-immunoreactive material among different neuronal subpopulations ${ }^{16}$. The presence of GABA-LIR in afferent calyces making contact with positive GABA-LIR cells may suggest that, as in the chick, GABA is synthesized in the hair cell and released from it, and it is 


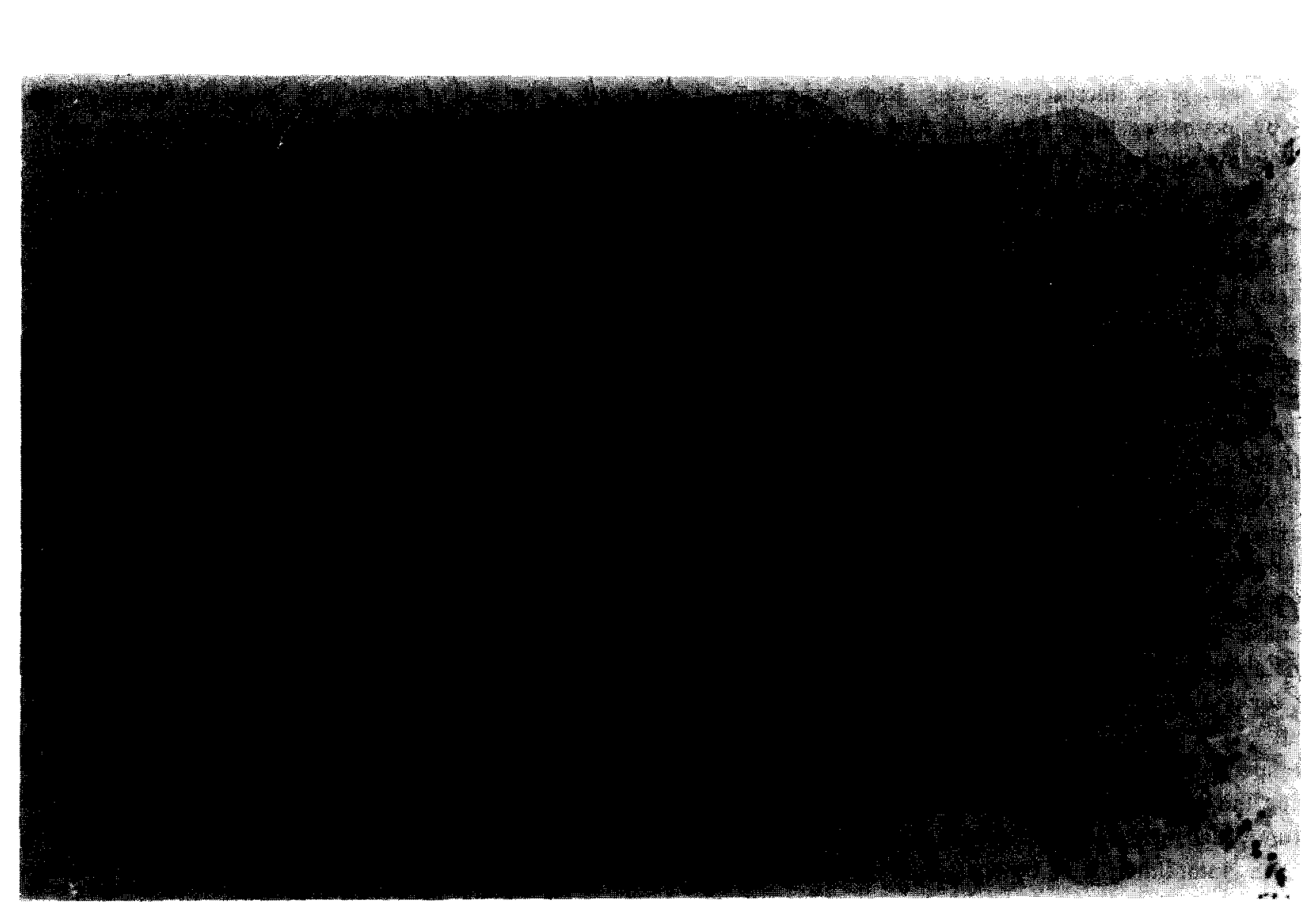

㿣

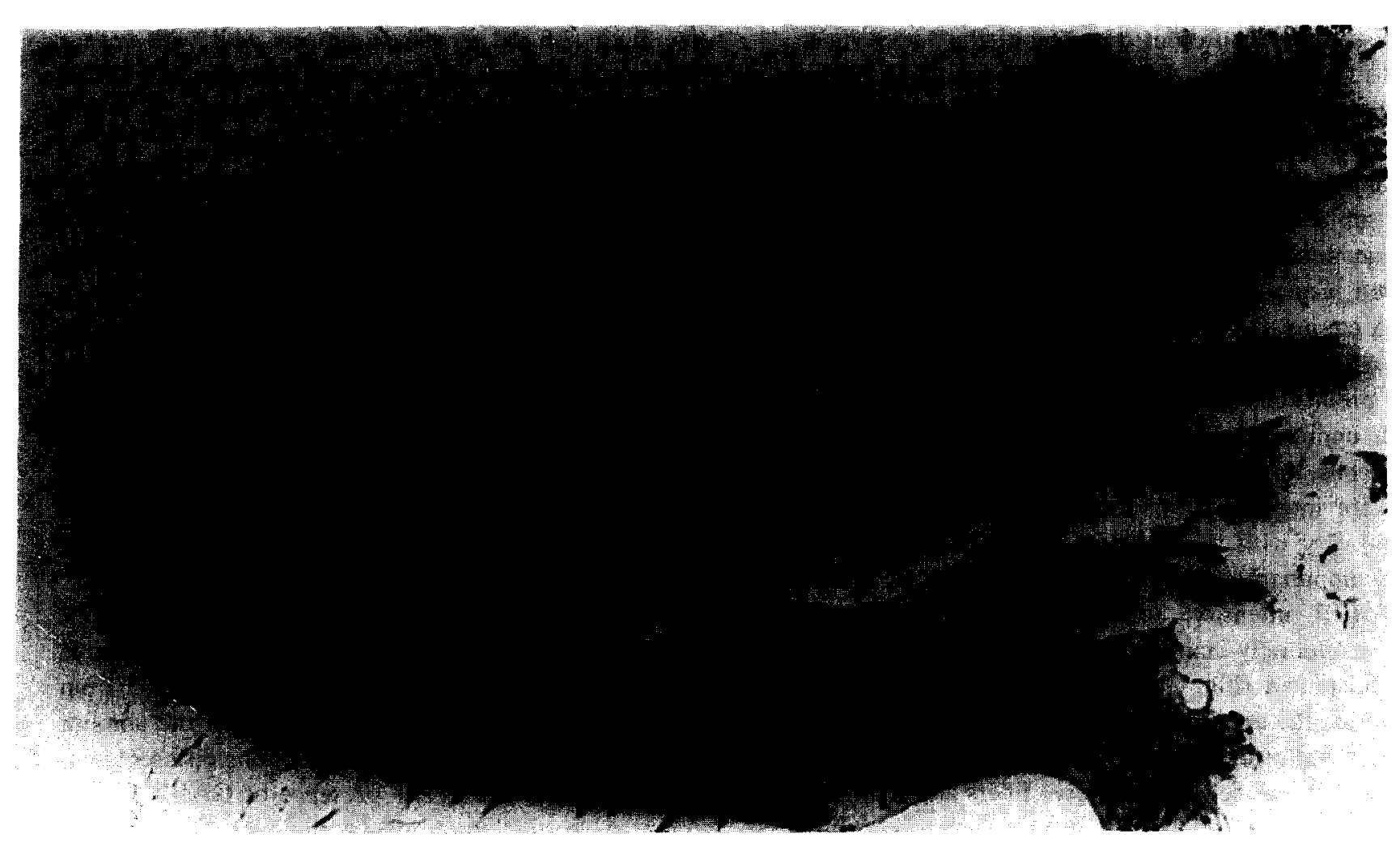
일

.

㓍

品

s.

ㅈ

IE

흥

흥

을

要

喜

i

.

偦

象产

它

政

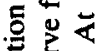

z

용 8 西

密

.

온.

앙

ह

辛

통

-

in 5

证要 


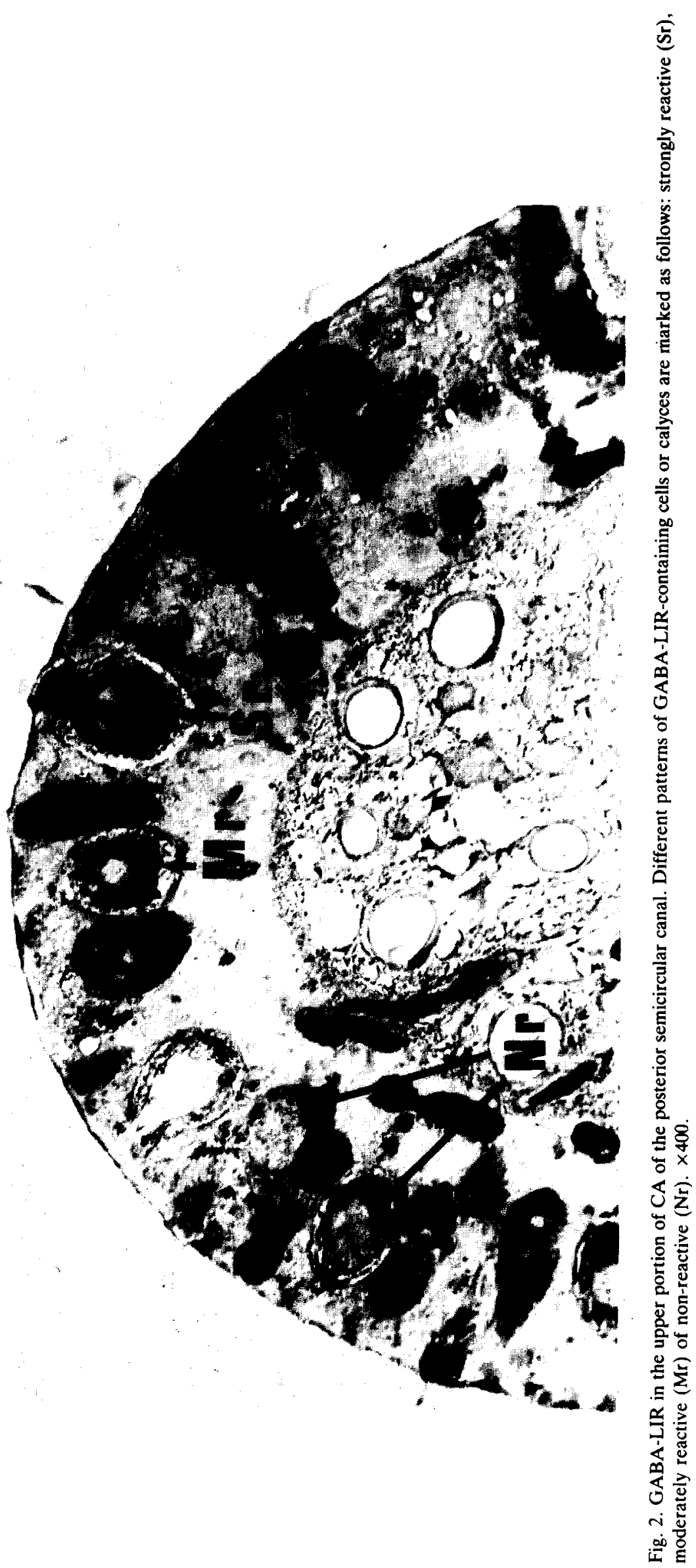




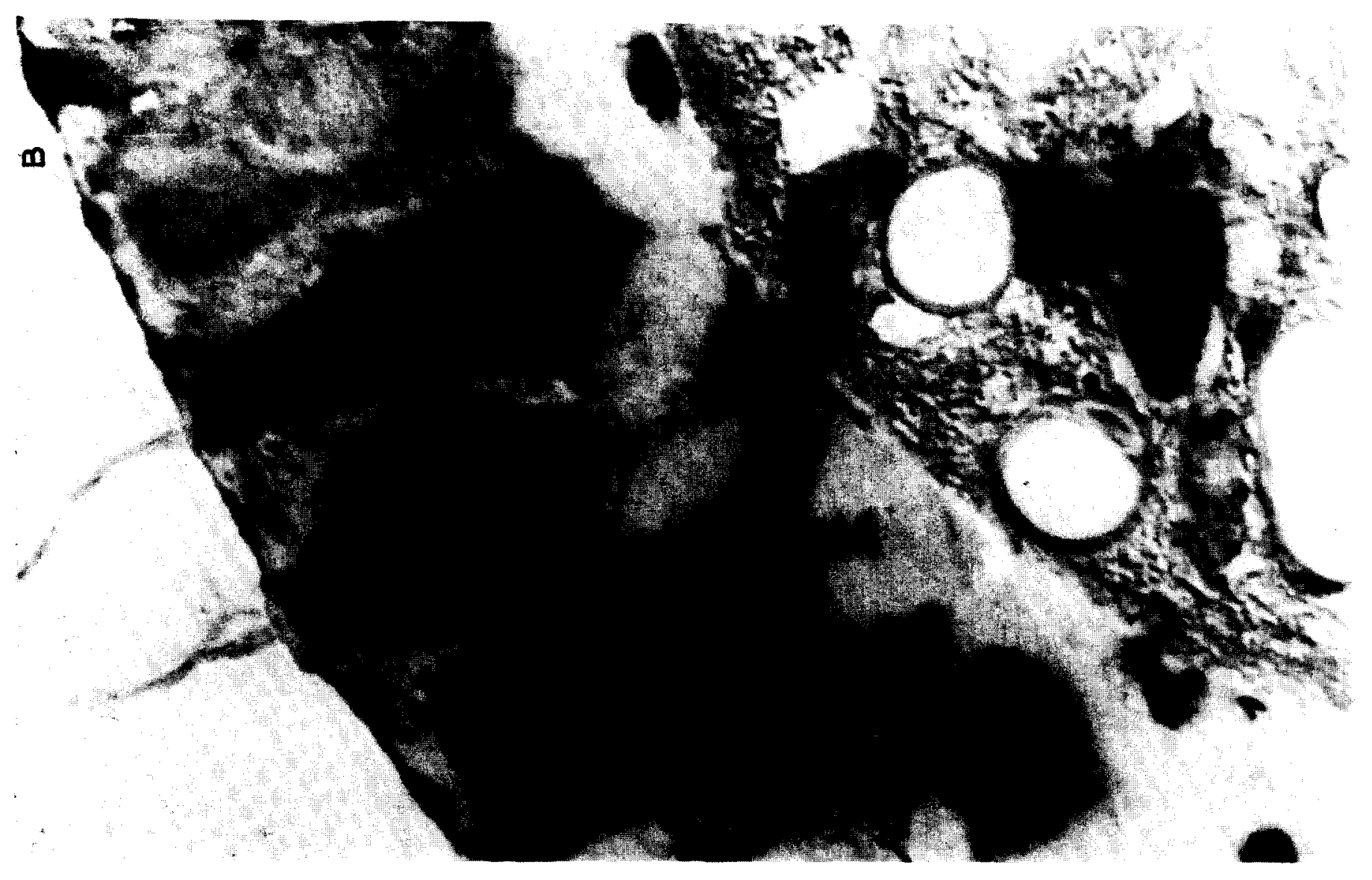

톤

步

블

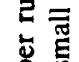

总

施

岁

in

氞

莺

$\exists$ 品

ณั้

5.

물

农

空

恵

咅

浗

政

䠖

它里

过

0.

可

跑

के

总

$\ddot{x}$

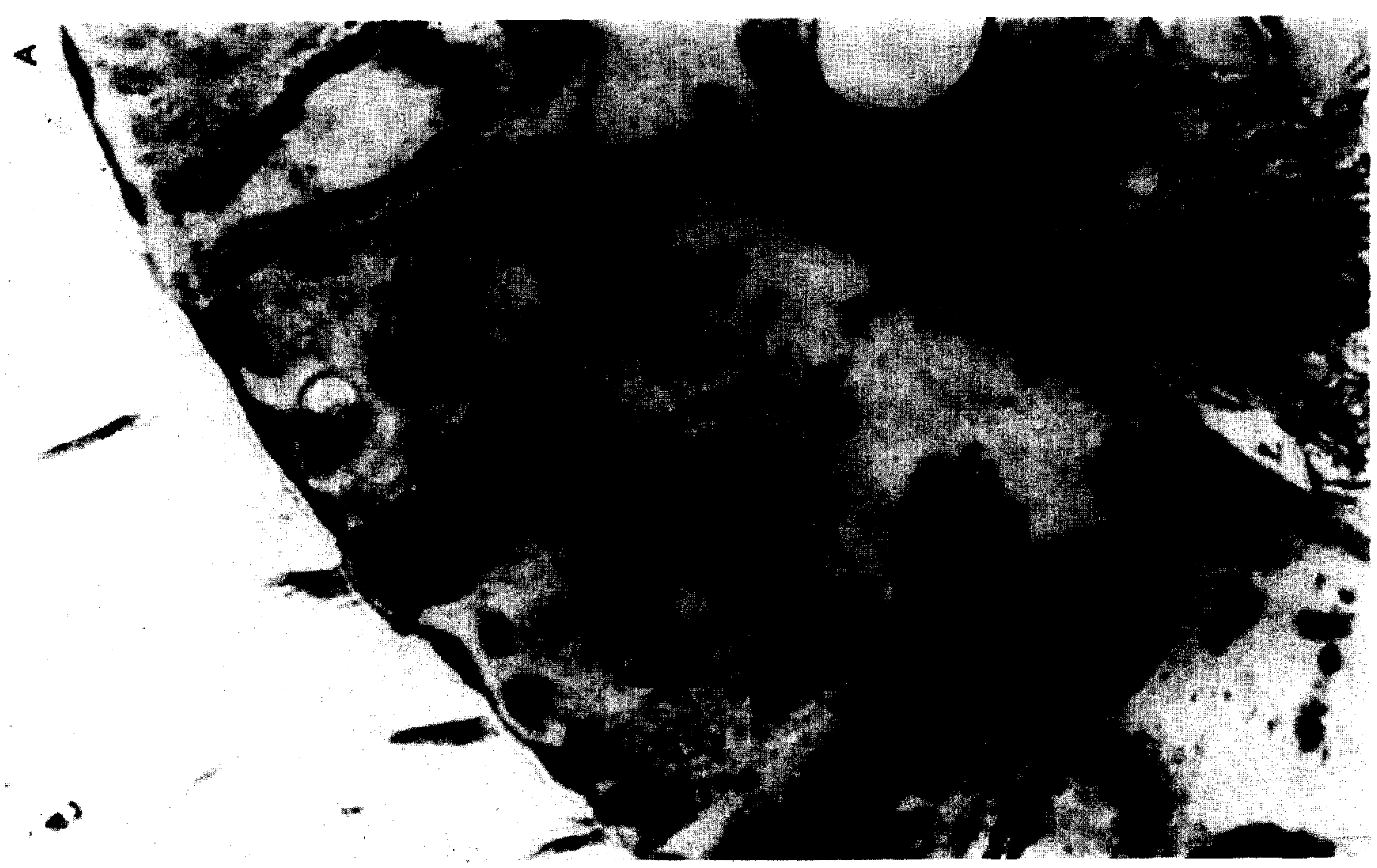

边泀 
degraded in the calyceal element by GABA-transaminase to terminate its action ${ }^{18}$. Experiments demonstrating GAD-LIR and GABA-T-LIR in progress in our laboratory may elucidate this notion.

As to the GABA-LIR only being in some calyceal afferents, recent results reported staining in all calyces but failed to encounter GABA-LIR in hair cells ${ }^{8}$. Although the former may postulate a modulatory-metabolic role for GABA, yet to be demonstrated, the latter can be attributed to differences in the techniques used or the source of antisera applied. In this respect, it would be very useful if all studies were done with the same kind of techniques and the same animal species.

In conclusion, this GABA-LIR in both hair cell I and

1 Annoni, J.M., Cochran, S.L. and Precht, W., Pharmacology of the vestibular hair cell-afferent fiber synapse in the frog, $J$. Neurosci., 4 (1984) 2106-2116.

2 Didier, A., Dupont, J. and Cazals, Y., GABA immunoreactivity of calyceal nerve endings in the guinea pig vestibule, Cell Tissue Res., 260 (1990) 415-419.

3 Felix, D. and Ehrenberger, K., The action of putative neurotransmitter substances in the cat labyrinth, Acta Otolaryngol. (Stockh.), 93 (1982) 101-105.

4 Flock, A. and Lam, D., Neurotransmitter synthesis in the inner ear and lateral line sense organs, Nature (Lond.), 249 (1974) $142-144$.

5 Guth, P.S., and Norris, C., Pharmacology of the isolated semicircular canal: effect of GABA and picrotoxin, Exp. Brain Res., 56 (1984) 72-78.

$6 \mathrm{Hsu}$, S., Raine, L. and Fanger, H., Use of avidin-biotinperoxidase complex $(\mathrm{ABC})$ in immunoperoxidase techniques, $J$. Histochem. Cytochem., 29 (1984) 4, 577-580.

7 Iturbe, A.G. and Meza, G., Asymmetrical development of GABA and acetylcholine synthesis in guinea pig vestibule, Int. J. Neurosci., (1986) 4 (suppl. 1); s 32.

8 López, I.,Juiz, J. M., Altschuler, R.A. and Meza, G., GABAlike immunoreactivity in the guinea pig vestibule: postembedding light and electron microscopy findings, Soc. Neurosci. Abstr., 15 (1989) 517.

9 López, I. and Meza, G., Comparative studies on glutamate decarboxylase and choline acetyltransferase activities in the vertebrate vestibule, Comp. Biochem. Physiol., 95B (1990) 375-379.

10 López, I. and Meza, G., Neurochemical evidence for afferent GABAergic and efferent cholinergic neurotransmission in the frog vestibule, Neuroscience, 25 (1988) 13-18.
II supports a putative role of GABA as an afferent neurotransmitter in the hair cells; GABA-LIR in fibers and calyceal terminals either contacting type I hair cell or alone may indicate a site of GABA degradation and/or a modulatory role of GABA, of as yet unknown mechanism, in the afferent calyceal endings.

Consejo Nacional de Ciencia y Tecnologia (CONACyT) México partially supported this work through a Doctorate scholarship to I.L. and Grant 200441 to G.M.; Generalitat Valenciana provided a post-doctoral Fellowship to J.M.J.; R.A.A. held a NIH Grant NS05785. The authors are grateful to Dr. Robert Wenthold of the Laboratory of Otolaryngology, (NIH) for providing the GABA antiserum.

11 Meza, G., Desarrollo asimétrico de la síntesis de GABA y acetilcolina en el vestíbulo, Bol. Med.Hosp. Inf. Méx,. 45 (1986) 65.

12 Meza, G., Cárabez, A. and Ruiz, M., GABA synthesis in isolated vestibulary cristae of chick inner ear, Brain Research, 241 (1982) 157-161.

13 Meza, G., González-Viveros, M.T., and Ruiz, M., Specific $\left[{ }^{3} \mathrm{H}\right] \gamma$-aminobutyric acid binding to vestibular membranes of the chick inner ear, Brain Research, 337 (1985) 179-183.

14 Meza, G., and Hinojosa, R., Ontogenetic approach to cellular localization of neurotransmitters in the chick vestibule, Hearing Res., 28 (1987) 73-85.

15 Meza, G., López, I., Paredes, M.A., Peñaloza, Y. and Poblano, A., Cellular target of streptomycin in the internal ear, Acta Otolaryngol. (Stockh.), 107 (1989) 406-411.

16 Pourcho, R. G. and Owzarkak, T., Distribution of GABA immunoreactivity in the cat retina: a light and electronmicroscopic study, Visual Neurosci., 2 (1989) 425-435.

17 Usami, S., Hozawa, J., Tazawa, M., Igarashi, M., Thompson, G.C., Wu, J.-Y. and Wenthold, R.J., Immunocytochemical study of the GABA system in chicken vestibular endorgans and the vestibular ganglion, Brain Research, 503 (1989) 214-218.

18 Usami, S., Igarashi, M. and Thompson, G. C., GABA-like immunoreactivity in the chick vestibular end organs, Brain Research, 418 (1987) 383-387.

19 Usami, S., Igarashi, M. and Thompson, G.C., GABA-like immunoreactivity in the squirrel monkey vestibular endorgans, Brain Research, 417 (1987) 367-370.

20 Wenthold, R.J., Zempel, J.M., Parakkal, J.M., Recks, K.A. and Altschuler, R.A., Immunocytochemical localization of GABA in the cochlear nucleus of the guinea pig, Brain Research, 380 (1986) 7-18. 